\title{
PERANCANGAN SISTEM INFORMASI IKLAN PRODUK HALAL MUI BERBASIS MOBILE WEB MENGGUNAKAN MULTIMEDIA INTERAKTIF
}

\author{
Barany Fachri \\ Universitas Pembangunan Panca Budi \\ Jalan Jend.Gatot Subroto Km 4,5 Medan \\ barany_fachri@dosen.pancabudi.ac.id
}

\begin{abstract}
Advertising is essentially one type of communication that other people are doing, turning in the sense of changing attitudes, traits, and behavior of people or people (communicant) in accordance with the will of the initiator of communication. Interactive Multimedia is a multimedia equipped with controller tools that can be operated by the user so that users can choose what is desired for the next process.
\end{abstract}

Keywords: Multimedia, E-Commerce, Communication, Advertising.

\begin{abstract}
Abstrak
Periklanan pada hakikatnya adalah salah satu jenis komunikasi yang bertujuan mempengaruhi orang lain, mempengaruhi dalam arti mengubah sikap, sifat, pendapat dan perilaku orang-orang ataupun seseorang (komunikan) sesuai dengan kehendak pemrakarsa komunikasi. Multimedia Interaktif adalah suatu multimedia yang dilengkapi dengan alat pengontrol yang dapat dioperasikan oleh pengguna sehingga pengguna dapat memilih apa yang dikehendaki untuk proses selanjuntya.
\end{abstract}

Kata Kunci : Multimedia, E-Commerce, Komunikasi, Periklanan.

\section{PENDAHULUAN}

Periklanan pada hakikatnya adalah salah satu jenis komunikasi yang bertujuan mempengaruhi orang lain. Majelis Ulama Indonesia (disingkat MUI) adalah lembaga yang mewadahi para ulama, zu'ama, dan cendikiawan Islam di Indonesia untuk membimbing, membina dan mengayomi kaum muslimin di seluruh Indonesia. Majelis Ulama Indonesia berdiri pada tanggal, 17 Rajab 1395 Hijriah[2]. LPPOM MUI adalah institusi yang dibentuk oleh Majelis Ulama Indonesia (MUI) pada 6 Januari 1989 di Jakarta yang berperan untuk menjalankan fungsi melindungi konsumen muslim di Indonesia dalam mengkonsumsi makanan, minuman, obat-obatan dan kosmetika yang halal dan menyehatkan[3]. Periklanan merupakan satu dari empat alat penting yang digunakan oleh perusahaan untuk memperlancar komunikasi persuasif terhadap pembelian dan masyarakat yang ditargetkan[4].

Promosi merupakan hubungan komunikasi antara penjual dan pembeli. Secara sederhana dapat dikatakan bahwa promosi adalah upaya untuk memberitahukan atau menawarkan produk atau jasa dengan tujuan menarik calon konsumen untuk membeli atau mengkonsumsinya[5]. Tujuan yang ingin dicapai dalam pelaksanaan dan penulisan tugas akhir ini adalah memberikan sebuah wawasan tentang makanan yang halal yang dapat dikomsumsi oleh masyarakat muslim dan logo MUI, agar tidak 
tertipu dengan label halal yang sekarang dapat salah gunakan oleh para pengusaha untuk mendapatkan keuntungan.

Adapun beberapa manfaat yang diharapkan dalam pelaksanaan dan penulisan tugas akhir ini antara lain adalah menghasilkan sebuah periklanan yang bermanfaat untuk membagikan sebuah informasi yang menarik tentang kehalalan semua produk makanan yang dijual baik di kedai sampah maupun di supermarker dengan kelulusan dari badan POM MUI yang sah.

\section{METODOLOGI PENELITIAN}

Multimedia interaktif adalah sebuah teknologi baru dengan potensi yang sangat besar untuk mengubah cara belajar, cara untuk mendapatkan informasi dan cara untuk menghibur. Dalam hal ini diskusi melalui multimedia interaktif merupakan cara baru untuk belajar yang paling populer dari multimedia pembelajaran[1].

\subsection{Desain Penelitian}

Pada tahap penelitian ini, yaitu sistem periklanan mengenai produk halal dan non halal, dilakukan hal-hal sebagai berikut :

a. Metode Observasi

Metode ini dilakukan dengan cara penulis melakukan pengamatan terhadap obyek yang akan diteliti.

b. Studi Literatur

Mempelajari buku referensi yang berkaitan dengan sistem pendukung keputusan.

c. Analisis dan Perancangan sistem

Menganalisis algoritma - algoritma berbasis interaktif

d. Implementasi/coding Mengimplementasikan kedalam bentuk program komputer.

Program yang akan dibangun menggunakan PHP, Web Mobile.

\section{HASIL DAN PEMBAHASAN}

Analisis sistem dalam penelitian ini menguraian dari suatu sistem perikalanan tentang produk halal konsep MUI dan produk yang tidak termasuk konsep MUI dengan maksud untuk mengidentifikasikan dan mengevaluasi permasalahan, kesempatan, hambatan yang terjadi dan kebutuhan yang diharapkan, sehingga dapat diusulkan perbaikannya[1].

Analisa solusi masalah untuk memperjelas pokok permasalahan sehingga lebih spesifik lagi dari masalah yang diteliti. Setiap masalah yang akan dipecahkan harus dicari solusi, fasilitas yang akan dikembangkan, penentuan jenis bahasa pemograman dan tujuan yang ingin dicapai dari proses pengembangan tersebut. Apabila proses pemecahan masalah dilakukan dengan benar maka akan dicapai hasil yang optimal[2].

Data yang dibutuhkan berupa data spasialyang berbasis komputer. Data tersebut di kumpulkan dan di kelola agar dapat menjadi sebuah hasil penelitian untuk menyusun sumber materi bahan penulisan[3]. Tahap perancangan sistem dapat digambarkan sebagai tahap untuk membangun suatu sistem dan mengkonfigurasikan komponen-komponen perangkat lunak dan perangkat kerasnya, sehingga 
menghasilkan sistem yang lebih baik[4]. Sedangkan use case diagram memfasilitasi komunikasi interface antara penguna dan komputer. Berikut ini use case diagram yang dibuat pada aplikasi perancangan[5].

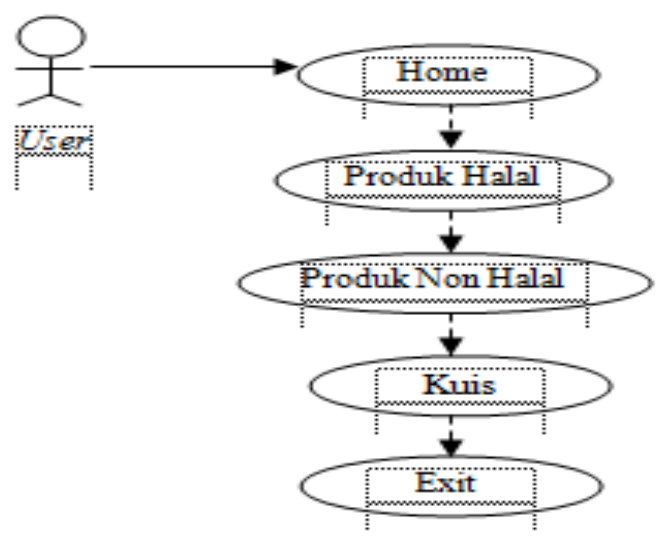

Gambar 1. Use Case

1. User mengakses aplikasi iklan dengan menampilkan dinding utama.

2. User mengakses halaman about me melihat perancang aplikasi.

3. User mengakses halaman produk halal versi MUI dan produk Non MUI untuk melihat iklan aplikasi.

4. User mengakses halaman exit untuk menyelesaikan sistem.

Implementasi basis data ini juga dibuat berdasarkan rancangan yang telah dibuat sebelumnya.. Proses terjadi pada program flash, dimana didalamnya terdapat sebuah skript yang akan berfungsi untuk melakukan operasi tersebut. Pada awal perancangan sistem, dengan hal yang pertama untuk membangun sistem aplikasi teknik periklanan dengan mengumpulkan data dengan studi literatur tentang produk halal yang memiliki settifikasi Mui dan Non sertifikasi Mui, langkah selanjutnya untuk membangun aplikasi adalah merancang tahap awal dengan perancangan sistem.

Pada tampilan halaman menu, di desain sesuai dengan perancangan sistem sebelumnya, dapat dilihat pada tampilan seperti gambar 2 :

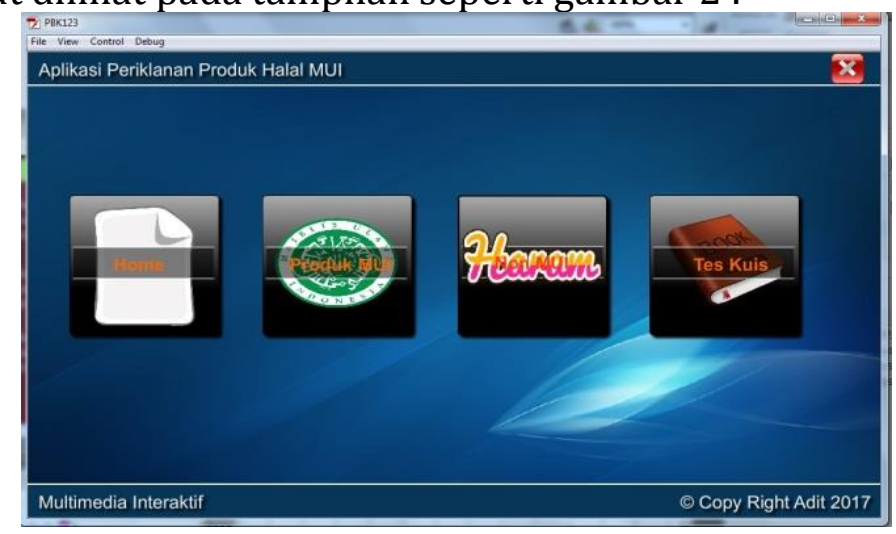

Gambar 2. Halaman Menu 
Pada halaman menu menampilkan perancangan desain selamat datang kepada pengguna, agar dapat memilih salah satu menu yang akan diakses, pada dinding menu aplikasi periklanan terdiri dari menu home, menu produk mui, menu produk non mui dan tes kuis untuk penguna untuk meningkatk wawasan. Pada halaman pengertian multimedia yang telah dirancang pada sesi sebelumnya, dapat dilihat pada tampilan seperti gambar 3:

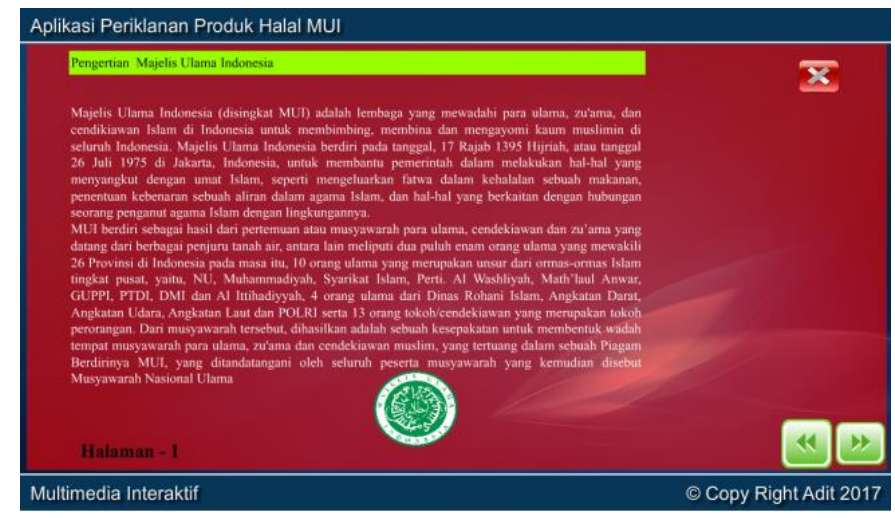

Gambar 3. Halaman Multimedia

Pada penjelasan sistem aplikasi pada halaman home, menampilkan desain pengertian multimedia, agar penguna dapat mengerti pengertian multimedia, tujuan multimedia dan manfaat dari multimedia tersebut. Pada halaman produk halal versi MUI yang didesain pada tahap perancangan sistem sebelumnya, dapat dilihat pada tampilan seperti gambar 4 :

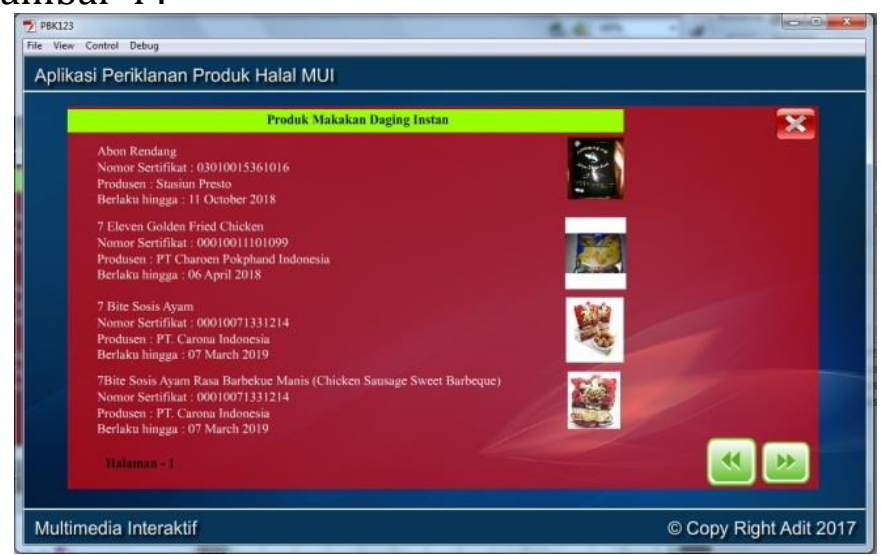

Gambar 4. Halaman MUI

Pada tampilan gambar diatas dapat dijelaskan bahwa isi dinding halaman produk halal setifikasi sah MUI memberikan penjelasan tentang nama produk halal dengan kategori daging instan yang dijual pada setiap super market yang terdekat pada rumah anda, dengan adanya informasi ini dapat membantu masyarkat untuk lebih teliti dalam membeli produk yang dibutuhkan. Pada halaman soal kuis yang 
didesain pada perancangan sistem sebelumnya, dapat dilihat pada tampilan seperti gambar 5:

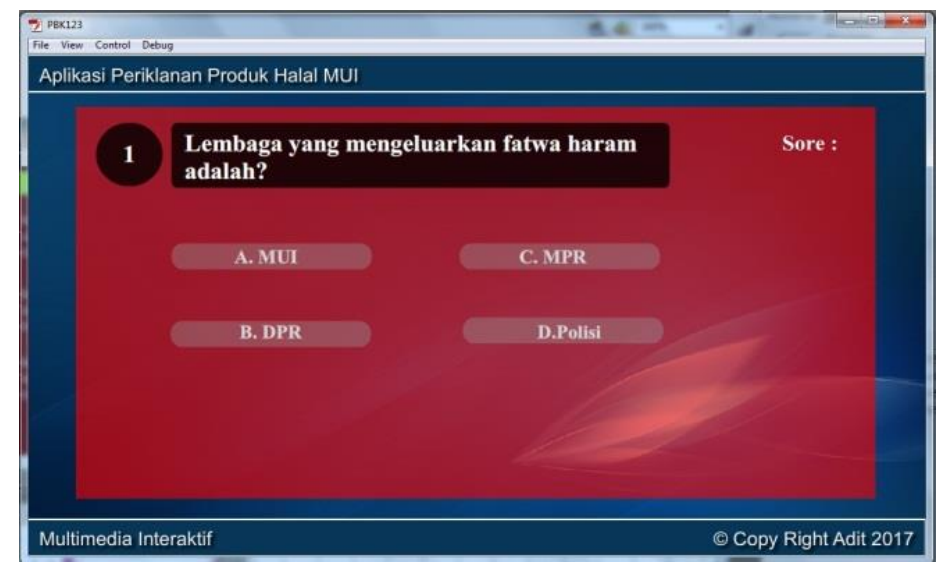

Gambar 5. Soal Kuis

Pada cara kerja sistem pada desain soal kuis pada gambar diatas dapat dijelaskan bahwa soal terdiri dari pilihan berganda, dimana penguna harus memilih salah satu jawaban yang benar agar penguna dapat mendapatkan poin pada setiap jawaban.

\section{SIMPULAN}

Berdasarkan hasil pembahasan yang telah dibahas pada bab-bab sebelumnya, maka penulis dapat menyimpulkan :

1. Perancangan aplikasi menggunakan software adobe macromedia flash cs5 untuk media multimedia.

2. Sistem aplikasi teknik periklanan berbasis multimedia interaktif menghasilkan sebuah iklan tentang produk-produk makanan halal dan non halal versi mui.

3. Hasil akhir dari penelitian ini adalah sebuah aplikasi teknik periklanan yang dikembangkan dengan media animasi.

\section{DAFTAR PUSTAKA}

[1] Andri, Gus. 2012. Strategi Pemasaran Dan Efektivitas Periklanan Dengan Menggunakan Metoda Komunikasi. Jurnal Manajemen dan Kewirausahaan. Volume 3, Nomor 2, Mei 2012, ISSN : 2086 5031

[2] Firdaus, Septiana. 2012. Perancangan Aplikasi Multimedia Interaktif Company Profile Generic. ISSN : 2302-7339 Vol. 01 No. 092012.

[3] Herdiansyah, M. Yanyan. 2013. Pembangunan Aplikasi Bantu Dalam Menghafal Al-Qur'an Berbasis Mobile. Vol. 2, No. 2, Oktober 2013, ISSN : 2089-9033.

[3] Aripurnamayana, M.Irfan. 2011. Rancangan Dan Pembuatan Mobile Learning Berbasis Android.

[4] Nandi. 2013. Pengunaan Multimedia Interaktif Dalam Pembelajaran Geografi Di Persekolahan. Vol. 6, No.1, April 2013.

[5] Hasrul. 2010. Langkah-Langkah Pengembangan Pembelajaran Multimedia Interaktif. Jurnal Medtek. Volume 2, Nomor 1, April 2010. 